\title{
Managing Resilience Against Climate Effects And Risks : The need For Insidious Socio-Economic Dynamics
}

https://doi.org/10.21272/sec.5(3).106-115.2021

Wendgoudi Appolinaire Beyi, ORCID: https://orcid.org/0000-0002-1590-530X

Associate Professor in Administrative Sciences, University of Ouahigouya, Philosophy Laboratory(LAPHI) \& Business and Organizational Management, Research Laboratory (LaReGEO), Burkina Faso

\begin{abstract}
This article examines the issues of climate change in the African context. The question is: what are the blueprints for addressing the dimensions of climate change in Africa and the implementation of SDG13 of the 2030 Agenda? The relief, the climate, the hydrography and the vegetation appear as fundamental bases in the restoration of the natural potentialities. The paradox of demography and the history of installations of cities without planning constitute "paths" of pertinent reflection in the constitution and exposure to risks. To restore the natural potentialities of practices and measures against drought, floods, destabilization of biotopes, overgrazing and deforestation appear as requirements. However, individual initiatives are futile without resorting to resilience supports, insemination forces and impetus impulses to structural engagement through the availability of green economy and individual commitments. The focal point of action for resilience appears with the consolidation of the economic being. This is what this reflection poses as a postulate: starting from the constitution of the awareness of needs to reveal in the subject his responsibility as a dynamic actor by necessity and / or by awareness of a need for action. This resilience appears with a co-construction of the external environment (physical, ecological, sustainability of resources, etc.) and the internal environment (consciousness, needs, new patterns, path and pattern of action, etc.) of the individual. Individual action becomes a socio-environmentally constructed act, socioculturally acceptable and socio-economically viable. The act is therefore part of a micro system, with springs and consequences on systems with a meso and macro dimension, therefore, included in the SDG13 of the 2030 Agenda. A guideline appears in the presentation of the research with a socio-economic actor positioning himself in his micro environment with instruments of collective action which consolidates socio-economic, environmental and climatic systems at the meso and macro level in Africa.
\end{abstract}

Keywords: SDG13, resilience, climate risks, green economy, africanisation.

JEL Classification: Z.

Cite as: Beyi, W. A. (2021). Managing Resilience Against Climate Effects And Risks: The Need For Insidious Socio-Economic Dynamics. SocioEconomic Challenges, 5(3), 106-115. https://doi.org/10.21272/sec.5(3).106$\underline{115.2021 .}$

Received: 23.07 .2021

Accepted: $\quad 10.09 .2021$

Published: 13.09 .2021 Copyright: (C) 2021 by the authors. Licensee Sumy State University, Ukraine. This article is an open
access article distributed under the terms and conditions of the Creative Commons Attribution (CC BY) license (https://creativecommons.org/licenses/by/4.0/).

\section{Introduction}

The implementation of the Sustainable Development Goals (SDGs) in Africa, Sustainable Africa 2030 still calls out because of its urgency and its problematic with regard to the specific challenges for Africa to assume its mobilization on enriching practices, innovative solutions and itinerant initiatives between predefined goals in the SDGs and emerging challenges.

The response to the possibility of the same diffuse problem in a variety of development objectives arises through legitimate reflection on a concern. What are the blueprints to answer the question of "dimensions of climate 
change in Africa and the implementation of SDG13 of the 2030 Agenda"? To respond to this concern, we believe that it is necessary to redefine a conceptual problematic for Africa, more focused on the question of people, their territory and their interactions : what are the practices, solutions and initiatives to be considered for counter drought, floods, cyclones, the destabilization of biotopes and life, and any harmful human behavior, in order to respond to the issues targeted by the 2030 Agenda ? These targets relate to several targets (objectives) of SDG and Agenda 2063 with a particularity on: objective 1, "Eradicate poverty in all its forms and everywhere in the world (specifically point 1.5-)"; Goal 11: "Make cities and human settlements inclusive, safe, resilient and sustainable (specifically item 11.b)" and Goal 13: "Take urgent action to address against climate change and its repercussions (specifically points $13.1 ; 13.2 ; 13.3$ )".

Thus, the debate around several questions seems important, in order to make the perspective of such concerns more explicit: What are the human practices on the issues of the expansion and control of climate risks in Africa ? What specific ecological transition for Africa in particular and its participation in the common fight against change and adverse climate effects in the world? What are the demographic challenges on the issue of risk prevention and climate change in Africa?

To address these questions, it is interesting for us to evoke on the one hand the question of apparently natural climatic facts with its human challenges (natural facts and data are not inevitable) and on the other hand questions of practices and human measures with their convincing and circumscribed resilience in Africa (facts and human actions as sources and artificial resources with apparent fatality). These two approaches ultimately provide us with an approach of critical and structural analysis on the strategic and operational links (resilience in the face of cyclical inevitability) with regard to Africa's contribution to a specific ecological transition to counter change and effects of climate change (African structural actions in the face of climate fate in favor of resilience).

\section{1) Methodology}

The knowledge of Africa's natural resources, its nature, its vegetation and its possibilities with a look at this generous past has been possible through documentary resources and a critical reading on the seals of the failures and the missed opportunities in the race to resilience.

The SWOT tool (Strengh, Weakness, Opportunities and Threats) made it possible to analyze the possible climatic, plant and socio-economic data in African areas and the possible objectives included in the SDGs13. We are interested in the strengths and weaknesses on the one hand and the opportunities and threats on the other hand in order to identify the processes and partners sufficiently relevant for the performance of actors and micro, meso and macro systems capable of holding sustainable development in Africa and elsewhere.

The concept of the individual as an economic actor from Adams Smith's perspective therefore offers an opportunity to pose the analysis with a relevant instrument of neoclassical theories of organizations. The theory of homo economicus appears to be a plausible concept for us in certain societies which are built on Maslow's scales of needs. It remains utilitarian in its conception and inscribes motives for action in the perspective of resilience. A theoretical reflection on documentary data and observation of the behavior of the homo-economicus: its parents and its sources and resources for action. From the analyzes, the reflection prefers to bring a boost to the invisible hand for an overall performance of sustainable development systems.

The purpose of this research is to start from a diagnosis of the strengths and weaknesses of the action environment of development actors in order to include the action of any actor in the enhancement of seizing opportunities and reducing all kinds of resilience and sustainable development processes.

There is a diagram of resilience based on the positioning of the actor in the resilience system in Africa. It is the reasonable economic actor who consolidates the deployment of the system through the improvement of the subsystems and its socio-economic, environmental and climatic flows.

\section{2) Facts and natural data are not inevitable}

Africa is bounded by oceans and seas, the Mediterranean to the north, the Atlantic to the south, the Indian Ocean and the Red Sea to the east. According to information from the Autodidact Quillet Encyclopedia (1975, p.640) on 
facts and natural data from more than forty years (without the influence of climate change) this continent has a specific climatic variant with four zones : the equatorial zone, the tropical zone, the desert zone and the Mediterranean zone. Climate regimes are taking hold on a massive plateau with obvious consequences for the organization of human activities and resilience to climate change. Hydrographic data envision a continent well served in sufficient water resources, constituting solid springs for a sustainable and equitable acclimatization of the continent. However, the imbalance remains apparent with unfavorable vegetation configurations in certain areas for human activity and development. In view of these natural facts, we propose adjustments that are predictive or constitutive of the achievements of influence at the climate level through a strategic (at the level of African, regional and national institutions) and operational (at the level of endogenous practices and measures) on the impulses to favorable climate change.

\section{At the level of the relief}

According to the Autodidact Quillet Encyclopedia (1975, p.640), the African relief is formed on a small plain with a massive plateau as the dominant form, on three large depressions : the Sahelian zone in the North, the Congolese basin in the Center, the Kalahari basin in the south. This massification is not inevitable and constitutes a reason for us to pose the postulate of a continent capable of adjusting and acting on the climate by making a sequence of space more or less homogeneous at the climatic and plant level. By maintaining an inclusive diversity of biotopes and human activities.

If the issue of climatic disasters remains a continent's problem, it is necessary to have a broad and comprehensive view in order to find the areas of disturbance and the practices likely to render obsolete the measures adaptable to the realities endogenous to each of the problems for each operating territory.

It is urgent at this level to adapt reforestation practices and human occupations taking into account the global potential and the possibilities of reconstituting the landforms towards their past natural dynamics, in a way that is complete and integrated with continental concerns.

\section{In terms of climate}

The equatorial zones cover the region of the Congo and the great lakes with constant heat (average temperature $24^{\circ}$ ) and daily rains (annual quantity of water is 2 to $4 \mathrm{~m}$ on average) according to information from the selftaught Encyclopedia Quillet (1975, p. 641). These are reference areas for reconstituting human activities around agriculture.

The tropical zones cover the region of Niger in the North and that of the Zambezi in the South with a fairly high heat and differences between winter and summer (extreme temperatures between $90^{\circ}$ and $43^{\circ} \mathrm{C}$ ) and rains during the season. Compared to the Canary Islands, which has the same climatic regime, precipitation is concentrated in winter and temperatures are cool (Self-taught Encyclopedia Quillet, 1975, p.641). This assume that these tropical areas of Africa can experience more favorable climatic changes with a cooling of the permanent winds (the trade winds) and by ricochet of the hottest season in these areas through green lungs.

Desert areas cover the Sahara in the north and the Kalahari in the south with large temperature differences between night and day and summer and winter. It freezes at night and there is at most $40{ }^{\circ} \mathrm{C}$ during the day, this is due to the extreme dryness of the air and the insufficient and irregular rapid rains absorbed by the soil or by evaporation (Autodidact Encyclopedia Quillet, 1975, p.642). Here too, to regulate temperatures and rapid evaporation, the air needs to be refreshed through the green lungs, strategic green belts and to counter the rapid absorption of water, it is necessary to invest first in experimentation. From "clay layers" of artificial dams hoping for future, long-term resilience with the sediments of artificial green lung vegetation.

The Mediterranean zones (warm temperate or subtropical west facade) cover Morocco, Algeria, Libya, Tunisia, Egypt in the North and the Cape in the South with hot and dry summers, mild and humid winters (Encyclopedia self-taught Quillet, 1975, p. 642). At this level, the cooling of the summer with green belts oriented for the protection of the winds and the comprehensive impact of the refreshments of the other zones will have to lead to 
an evolution of Mediterranean climate, climate type (Csa) with hot summer towards a type of climate (Csb) with cool summer.

At this climatic level, it is ultimately a question of catching up with outdated climatic regimes by acting on human practices oriented in the long term and integrated at the scale of the continent.

\section{At the level of Hydrography}

The equatorial and tropical regions therefore have abundant rains, which gives rise to large rivers : the Nile with $6470 \mathrm{~km}$ and its sources in the great lakes of East Africa; Niger with about $4000 \mathrm{~km}$ and its sources in Fouta-Jalon (The Congo river with $4200 \mathrm{~km}$ spreads out along the Congolese basin. Africa is specific with powerful rivers and abundant lakes. Victoria lakes, Albert, Edouard feed the Nile, Lake Tanganyika, the Congo through the Loukouga, Lake Nyassa, the Zambezi through its tributary the Chiré (Autodidact Encyclopedia Quillet, 1975, p.642).

However, it is important to survey the Mediterranean and desert areas with rivers and artificial lakes to restore climatic balance. If man can build intercontinental highways, invest in them in time and resources, he can also ultimately save Africa with long-term artificial tributary projects on the edges of the great precipitates of the sources of waters. By disseminating dams also in arid zones, it creates jobs and plant cover against desertification.

By developing rivers and lakes against the movements of dry winds, Africa develops humid air in tropical and Mediterranean areas likely to bring a more flexible climate with more realistic and inclusive benefits for all of Africa and the world.

\section{At the level of vegetation}

The equatorial zone was that of dense forest with an abundance of plants with sizes and evergreen foliage (Encyclopédie autodidacte Quillet, 1975, p.643). However, it is important to establish an ideal of plant cover with the framing of technicians and thus produce and reproduce the ideal or the return to criteria of plant cover to be popularized.

The tropical zones included more sparse and deciduous forests, with a drought and a savannah made of tall grasses, trees adapted to drought (baobabs, shea butter, cheese) according to the Autodidact Encyclopedia Quillet, (1975, p. 644). Here, the solution is not to adapt with resistant trees but to constitute controlled areas of plant cover by alternating adaptations and brakes with trees with branches and foliage against hot winds and favorable to soil sedimentation.

The desert areas have experienced rare vegetation, woody and hard to resist evaporation with tufts of rare and hard grasses, thorny acacia, stunted bush, etc. (Quillet Autodidact Encyclopedia, 1975, p.644). Here too, we assume that evaporation must be countered with a series of green belts and progressive framing of plant cover identical to what we have just proposed at the level of the tropical zone.

The Mediterranean areas have experienced arborescent vegetation (state of scrubland and scrubland, cork oak, holm oak, myrtaceae, etc. meadows with short grass and fragrant plants) according to the Self-taught Encyclopedia Quillet (1975, p. 644). Here too, it is a question of promoting a progressive framing of the practices of plant belts parallel to climatic hazards towards the type of equatorial forest.

Although the realities of relief, climate, hydrography or vegetation appear inevitable today with human actions compared to what was less than fifty years ago, the challenges still remain to be seen : levels of facts and actions that humans can observe to reverse or counter the patterns of catastrophic climatic phenomena.

\section{3) Human facts and actions as artificial sources and resources in the face of apparent fatality}

On human facts and actions, the findings already apparent show that population growth increases urbanization and the impact of cities or urbanization on the environment.

\section{African demography as a source of discord}

The question of demography is implicated in a correlative way with the evolution of deforestation in Africa. It is above all a rural culture of ignorance and recklessness in the face of great vital issues. 
Bruno David, president of the National Museum of Natural History, Christian Bordé, physicist and Marie-Lise Chanin, of the Academy of Sciences are calling for the vigil on fertility in Africa through funding for the contraception program. However, we note that China and India are the most populous in the world without attracting a "wake-up call" from scientific analysts. It will therefore be the perception of the practices and behaviors of Africans in the face of vital issues for humanity that constitutes a mobilization of plural points of view on Africa.

With studies, published by Planetoscope (2019), Africa "currently has the highest fertility rates" certainly, but "it is also the least densely populated continent", the projection assumes that in "2100, it is will always be less than Western Europe and Asia ". It is therefore a favorable period for the redeployment of cities on safe natural sites.

In addition, according to the sources of the Population Division of the United Nations system, "among the 10 countries currently most populated, only one is in Africa (Nigeria), five located in Asia (Bangladesh, China, India, Indonesia and Pakistan), two in Latin America (Brazil and Mexico), one in North America (United States) and one in Europe (Russian Federation). However, among the ten fertility rates in the world presented by IndexMundi (January 2018), Africa breaks the record with 10 countries : in 2017, Angola, Niger, Mali with the index 44, Uganda with the index 43, Zambia with index 42, Burundi, Burkina Faso, Malawi with index 41, Somalia with index 40, Liberia with index 38.

What reports should therefore be made on the link between demography and the issue of climate risk prevention and climate change ? These galloping demographics especially at speed and rural exploits (the absence of birth planning with reconciliation of own resources) raise the question of the balance of biotopes and natural resources with regard to various practices and aggressive human activities on the environment and its natural resources in unfavorable regions. The control of this demography with practices and measures adapted to the realization of correlation between birth rate, human vitality and vitality of biotopes would obviously be a rational and natural basis for an individual commitment of the populations in order to counter this apparent fatality and anchored in the representations. Humans must no longer adapt or simply reproduce adequate, but resilient biotopes.

We therefore pose the human fact as an important fact, which is why we believe that a global strategy that involves a structural dimension of the whole of Africa and operational axes that concern individual responsibilities engaged in practices and incentives. And economic issues constitute an adequate response in Africa against climate change.

The demographic fact also implies the construction of cities in compliance with urbanization standards. The history of demographic governance seems to share correlations so well with the history of cities through questions of territory and population.

The history of cities as a shadow of anguish

To also understand the risky situation of cities in Africa on the effects of climate change and natural disasters, we have to go back in history and the economic issues that gave rise to the choice of the place of installation and population of these cities. This story reminds us that cities in Africa and their populations are justified by the proximity of water basins or lakes favorable to human activity. Public institutions subsequently consolidated this logic of urbanization without having or having given themselves the means to build a sanitation and drainage policy capable of responding, adjusting or countering the consequences in the face of possible natural disaster. Thus, natural disasters appear at this level more as a form of incapacity for human resilience than extraordinary rainfall on the African continent. Floods are the perverse effects of the proximity that has become promiscuous between the territory of man and the territory of water.

From the hydrographic proximity showing resilience with demographic issues, we are in an uncontrolled promiscuity : it is therefore necessary to rectify the urbanization plans and emerging human settlements. According to the consulting firm Verisk Maplecroft, among the most exposed cities in the world by 2035, fifteen (15) African capitals are mentioned. The CCVI index (Climate Change Vulnerability Index) thus gives for six exposed African cities : Kampala (5.1\%) in Uganda, Dar-es-Salaam (4.8\%) in Tanzania, Addis Ababa (4.3\%) in Ethiopia, Abuja (4.5\%) and Lagos (3.5) in Nigeria, Luanda (3.7\%) in Angola). The study reveals a correlation 
between the risk of climate catastrophes and the rate of population growth at this level. It may be necessary to think of duplicating cities on heights that meet modern urbanization standards.

If from demography to the history of cities there is only one fact, the human fact, it is important to find human issues of the reconstitution of good patterns to African resilience in the face of the fate announced on the continent : in terms of the risk of indigence. Richard Munang \& Jesica Andrews (2014) pointed out that "across the continent, many communities have already started to build resilience by stimulating existing ecosystems and available natural resources". It is up to each African to contribute to the resilience of the continent through structural proposals.

\section{4) Resilience in the face of cyclical inevitability}

The human challenges facing African resilience lie in the practices and measures against drought, floods, the destabilization of biotopes, overgrazing and deforestation, all of this through a citizen-oriented commitment from each actor on the continent.

\section{The agenda of practices and measures in the face of drought}

To overcome the drought, it is important that the populations explore the policies of sedentarization of young people in rural areas, more particularly in the affected territories through the achievements or policies of rulers in the promotion of green jobs. Achievements of oriented green belts in the continent could reconvert the dry winds and bring sediment to the soils. Support for the achievements of personal and individualized green sites could empower and create economic nodes in order to boost the development of green territories. Thus, Africa wins by structuring this struggle through the activities of structural initiatives at the level of institutions, as well as popular measures and practices.

This response to drought can be constructed with the prospect of mitigating the effects of flooding through water harvesting actions planned on continental, regional, national and local scales.

\section{The agenda of practices and measures to deal with floods}

To overcome floods, institutions and municipalities must anticipate to ensure the proper use of water and its runoff by building cities on low-risk plateaus with receptacles for water flow to the outskirts. These waters can contribute in some cases to enrich market gardening activities in order to regulate its balance. By postulating that today's action is a gesture for the future, it is obvious and rather urgent to split the cities on secure territories with modern standards of urbanization, in order to include this project in long term, and also achieve the feat of saving future generations from the challenges of flooding.

\section{The agenda of practices and measures to address the destabilization of biotopes}

For concerns about the destabilization of biotopes and living things, it is important to note that cities have already destroyed a large number of forest areas and freshwater lees when we refer to the historical processes of settlement around the areas. It is therefore interesting to plan for green programs in African habitats, which is possible with regard to the very horizontal development plan for towns, it is therefore "reintegrating the forest" into the vast yards to guarantee the diversity of the biotope and its environment. Impact on air purification in both urban and rural areas. Municipalities can therefore consider imposed plans for biotopes in cities with fiscal responsibilities in the event of resistance from certain individuals.

\section{The agenda of practices and measures in the face of overgrazing and deforestation}

To overcome overgrazing and deforestation, it would be wise to consider diversified biotopes adapted to each environment of inscriptions of types of human activity. Thus, by engaging the interest of the actor on the beneficial sources of his involvement, it appears likely that the reforestation projects will have a viable and lasting basis. For example with a green value chain: a given variety of tree, plants, plantation for such use of leaves (animal or human consumption) and fruits for such territory can give both a dynamic and an interest for the action structurally planned at the level of the actor in his system of action. 


\section{The agenda of practices and measures for African citizen engagement}

For the day before and citizen engagement around the issue of forecasts and anticipations, three lines of thought were already engaged in the Overseas Notebooks: the first related to the measurement of climate change (with 744 meteorological stations against 3800 in Metropolitan France) with the risk of inability to carry out forecasts, analyzes and regional and African interpretations; the second concerned the "complexity of the atmospheric dynamics at work on the African continent" with limits of the scales of observations retained in time and space (meanings of temperatures or precipitations for the peasants, the references of the system climatic to localized or located in a regional or African climate change); the third takes into account the neglect of the human variable often left to iterative adjustment to optimize individual returns or sectarian measures leaving aside the resilience capacity of the continent. We can situate our perspective at this level on three axes :

For the first axis, it is to register and multiply on the African level inclusive pan-African meteorological stations for also national use in the service of monitoring climate change at the level of the continent.

For the second axis, it is a question of including measures of precision and sensitization on the meanings of general meteorological data in Africa in order to make available to users of endogenous action skills : thus, peasant farmers or breeders, the citizen or the social actor will be able to carry and disseminate the appropriate practices and measures for generations.

For the third axis, the deployment of solidary and inclusive continental policies and measures, as well as mastered, shared and optimized practices for resilience are, among other things, the foundations for creating a strategic and operational space adapted to the African contribution for Africans and the world. Thus, we call for controlled structural actions and measures.

\section{5) African socioeconomic and structural actions in the face of climate fate in favor of resilience}

Despite the climatic fatality announced in Africa, there are many actions in the continent in favor of a certain resilience in response to this problem. However, the disparate and often conflicting efforts break with the synergy of good African resilience. We must therefore find a support for resilience, its foundations for African-style insemination, the sources of the impetus for structural commitment to this resilience, in order to also have a green economy and individual commitments around structural fact.

\section{Support for resilience}

To meet Goal 13: Take urgent action to combat climate change and its repercussions. Point 13.1: Strengthen, in all countries, resilience and adaptation capacities to climate hazards and climate-related natural disasters.

International negotiations on climate policies in the world, particularly in Africa and with the countries of the North, must materialize on the establishment of young people in their regions. By creating an environment of generalized movement of individual productions of green plots, prosperous for oneself and for their offspring, the action facilitates the creation of jobs and the beneficial establishment of young people in their land. Climate action in Africa takes migration action upstream. In the Sahel, a young person with a green plot can make subsidies by selling the leaves with the livestock owners in the dry season and by reselling the fruits of the trees on the market. This can complement its often seasonal activities.

\section{African insemination of resilience}

To meet the sub-objective: 13.2 Incorporate climate change measures into national policies, strategies and planning

African negotiations on climate policies must change the status of the African Union as a federal state or at least emerge an authority capable of acting with full authority on the axes of resilience in the territories. The prerogatives of this entity may lie in the assessment of the challenges of policies, plans and practices in terms of the development of safe spaces, of empowered territories. This can also trigger the growth of green economies based on stimulation, support and performance evaluation in specific territories according to technical 
frameworks. The action must make it possible to integrate inclusive climate logic for Africa by enhancing integration and the values of lasting solidarity and inclusion.

\section{Structural commitment to resilience}

To meet Goal 11 : "Make cities and human settlements inclusive, safe, resilient and sustainable. 11.b By 2020, significantly increase the number of cities and human settlements that adopt and implement integrated policies and action plans for the inclusion of all and the rational use of resources climate change adaptation and mitigation and disaster resilience, and develop and implement, in line with the Sendai Framework for Disaster Risk Reduction (2015-2030), comprehensive management disaster risk at all levels "

To the designer and technician : design and plan local development plans by possibly integrating the logics that we have proposed, at the limit, submit to an African commission the examination of these plans with respect for African standards for the development of structural green economies.

It is up to the institutions in charge of urbanization and town planners to rebuild urbanization plans for cities, establishments and territories that take into account the dimension of natural disasters to protect populations. By paying particular attention to the new urbanization processes, it is obvious that we are avoiding the mistakes of the past which consisted in building cities around water basins and thus blocking the natural voices to the circulation of water.

\section{Resilience through a structural green economy.}

To meet Objective 1: "Eradicate poverty in all its forms and everywhere 1.5 By 2030, strengthen the resilience of the poor and those in vulnerable situations and reduce their exposure to extreme weather events and harsh conditions. 'other economic, social or environmental shocks and disasters and their vulnerability'.

The practices and employment policies of structural green economies must make it possible to combine alternative creations of recognized, defended and valued heritage. From green employment to the fight against climate change, public action must appear with mobilizations, subsidies and support for the creation of plots of seedlings, orchards, technical plantations, from start-up to construction : through integrated programs of private and public green spaces in rural areas according to an African, national, local and technical framework plan.

Good practices would be the emergence of green plots in arid zones, symbolic orchards to attract and arouse a popular continuum, as well as the definition of zones of protected belts.

\section{Individual commitment to resilience}

To respond to sub-objective 13.3 "Improve education, awareness and individual and institutional capacities with regard to adaptation to climate change, mitigation of its effects and reduction of its impact and warning systems quick".

Citizens must and can govern watches and stays for the implantation of values, practices, measures through the emergence of "movement or grouping of generational structural green economies $\mathrm{x}$ and $\mathrm{y}$ ", "generation of lobbying for green in critical territories", "the bailiffs of green inheritances ", and so on.

In this perspective, the peasants must be strongly associated with the diversification of reforestation: a child, an inheritance of land, a plot of plant (with good fruiting) also useful for breeding.

In order to create a burgeoning African space displaying biotopes useful to man and humanity, projects for the parcelling out of the peasants' environment can be deployed with self-responsibility for its vitality, its viability, and its sustainability: the economic fact can be constructed and highlighted in the effectiveness of the deployment. With the emergence of nurseries, sites with economic benefits, the factory of fencing or making fence screens, etc. a job or a parallel occupation is possible to make dynamic the operations of appropriation of practices and measures.

Finally, can Africa dare? Consider large controlled and momentary migrations (ten years) of pastoralists from one area to another and orient these breeders in desert areas on the African climate alternative of building green belts 
integrated with the prospects of boosting the springs of climate balance. This, in order to build more robust orchard and belt strategies in given climatic spaces?

Funding: self-funded.

Author contribution: conceptualization, Wendgoudi Appolinaire Beyi; data curation, Wendgoudi Appolinaire Beyi; formal analysis, Wendgoudi Appolinaire Beyi; funding acquisition, Wendgoudi Appolinaire Beyi; investigation, Wendgoudi Appolinaire Beyi; methodology, Wendgoudi Appolinaire Beyi; project administration, Wendgoudi Appolinaire Beyi; resources, Wendgoudi Appolinaire Beyi; software, Wendgoudi Appolinaire Beyi; supervision, Wendgoudi Appolinaire Beyi; validation, Wendgoudi Appolinaire Beyi; visualization, Wendgoudi Appolinaire Beyi; writing - original draft, Wendgoudi Appolinaire Beyi; writing - review \& editing, Wendgoudi Appolinaire Beyi.

\section{Conclusion}

In the African continent, climatic facts and data are seen as natural fatalities on which the practices, measures and action of the individual seem to be resigned to building a logic of adaptation and not of reaction on these climatic facts. Each climate zone builds action prototypes that do not contribute to resilience in solving the problem of climate change and natural disasters. However, after our analyzes, we can conclude that human action through the use of reason, by rationalizing practices and measures for resilience in the African space, climate challenges can find an extraordinary (and miraculous) outcome for future generations. If Africa is therefore often called upon on the demographic and climate issue, it must react in common and united action to overcome the critical evidence. Africa must act and act for others too.

Africa is not however the exception of risks, according to the climate risk index, the ten (10) countries most affected by extreme weather events (between 1997 and 2016) are not located in Africa (Honduras, Haiti, Myammar, Nicaragua, Philippines, Bangladesh, Pakistan, Vietnam, Thailand, Dominican Republic) Our findings and recommendations at this level can also be used by these nations so that humanity can finally win a fight that is never won by the arrangements and practices of a single international or national institution, a continent, a nation, etc.

There is of course a diagram of resilience based on the positioning of the moderating actor of the system with efficient flow subsystems for resilience in Africa. The economic actor that we have defined can in its deployment improve its micro environment and thus give a boost to the improvement of socio-economic, environmental and climatic meso and macro flows.

Modestly, we believe that the SDG targets of Agenda 2063, our findings and recommendations deserve special attention in order to revitalize African institutions and their solidarity and inclusive measures in the treatment of common problems on global warming. Floods here, drought there! Finally, a simple question seems to arise: Why Africa remains powerless in the face of all these blessings abundantly invested with rains by our God in the face of our cries?

\section{References}

1. Alain François \& Mohamed Taabni (2012). Africa facing climate change. Les Cahiers d'Outre-Mer. Available at: [Link].

2. Index Mundi (2018). Thematic Map, Population-World. Available at: [Link].

3. Planescope (2019). Birth in the world, World statistics in real time. Available at: [Link].

4. Richard Munang and Jesica Andrews (2014). Africa facing climate change, agriculture special edition. Africa renewal. Available at: [Link].

5. Verisk Maplecroft (2021). Risk indices, climate change exposure. Available at: [Link].

6. Adams Smith (1776). Wealth of Nations, in Philippe Jaudel and Jean-Michel Servet, Economica, 2000. Available at: [Link].

7. Abraham Maslow (1943). A Theory of Human Motivation. Psychological Review, n50, p. 370-396. Available at: [Link]. 
8. African Union Commission (April 2015). Agenda 2063: The Africa We Want. Addis Ababa, Ethiopia. Available at: [Link].

9. David Eckstein, Vera Künzel and Laura Schäfer (November 2017). Germanwatch and Munich RE NatCatService, Global Climate Risk Index 2018, trad. Marie Kassmann. Available at: [Link].

10. Sustainable Development Goals (2015). Available at: [Link].

11. Self-taught encyclopedia Quillete (1975). Available at: [Link]. 